\title{
AWARENESS AND BELIEF REGARDING BREAST CANCER AMONG WOMEN LIVING IN SELANGOR, MALAYSIA
}

\author{
Hasanain Faisal Ghazi 1, Mohammed A. AbdalQader1, Mohammed Faez Baobaid1, Tiba Nezar Hasan ${ }^{1}$, \\ Povaneshwari A/P Maratha Pillai ${ }^{1}$, Mohd Rohaizat Hassan ${ }^{2}$, Han Yung Wen ${ }^{3}$ and Alabed Ali A. Alabed 4 \\ ${ }^{1}$ International Medical School, Management \& Science University, Selangor, Malaysia. \\ 2 Department of community health, Univeristi Kebangsaan Malaysia Medical Centre, Kuala Lumpur, Malaysia \\ ${ }^{3}$ EcoSoul Clinic, Setia Alam, Selangor, Malaysia. \\ ${ }^{4}$ Head of Community medicine department, Faculty of medicine, Lincoln University College, 47301, Petaling Jaya, \\ Selangor, Malaysia
}

\section{Corresponding author: Mohammed A. AbdalQader}

Email: mohd_abdalqader@msu.edu.my

\begin{abstract}
Breast cancer is one of the leading causes of mortality among women. The aim of the current study was to find out the level of awareness and belief about breast cancer among women in Selangor, Malaysia. A cross-sectional study was conducted among women living in Selangor aged 18 to 65 years old, with a total of 483 participants. A validated questionnaire regarding awareness and belief was used. The questionnaires consist of 25 questions comprising of sociodemographic, history of other diseases, awareness and belief. The prevalence of poor awareness among women was 63.4\%. while the poor level of belief was $84.7 \%$. There was a significant association between awareness and educational background, family history of breast cancer $(P=0.001, P=0.032)$ respectively. The association between awareness and belief was significant $(P=0.02)$. As a conclusion: There is a high level of poor belief and poor awareness among women in Selangor, Malaysia regarding breast cancer. Source of information such as the internet plays a major role in breast cancer prevention, and the majority of them do not know the technique of breast self-examination. More health promotion is needed to target general population through big campaign of awareness.
\end{abstract}

Keywords: Awareness, belief, breast cancer, educational level, Selangor, Malaysia.

\section{INTRODUCTION}

Breast cancer is one of the most heated topics of debates among the healthcare community as well as the general public. According to the World Health Organization (WHO), breast cancer is the most common cancer involving high mortality rates among women with reported of 627,000 deaths in $2018{ }^{1}$.In Malaysia, breast cancer among women is still at large with a reported case of 7,593 Compared to 2018 with a reported case of 6,378 , there is a significant increase in reported cases $^{2}$.

A previous study done in Penang, Malaysia among 200 women who studied in a public university was found out that the level of awareness about breast cancer was still inadequate $(60.7 \%)^{3}$. This study concluded that the level of awareness among Malaysian, especially young adults was still not sufficient even though they belong in a group of people with the highest level of education (Tertiary). In a research with respect to breast cancer understanding, results showed that more than two-third of respondents realize that painless breast lump (72\%), secretions from nipples $(74.5 \%)$, mass in the armpit $(78.5 \%)$ and changes in the size of breast (81.5\%) as signs and symptoms of breast malignancy. Even so, only half the number of respondents agreed that retraction of skin around the breast (58.5\%) as one of the signs and symptoms ${ }^{3}$.In Malaysia, study done in
Shah Alam City among 250 women carried out by (Al-Dubai et al., 2011) ${ }^{4}$ has shown that majority of the respondents acknowledged genetic or family history as able to contribute to the possibility of getting breast cancers evidenced by $88 \%$, followed by smoking (65\%), consumption of alcohol $(56.8 \%)$ and prolonged exposure to radiation $(67.2 \%)$.

Apart from that, there had been few common faiths of mythical causes of cancer that can be used as a tool to survey the general public belief in breast cancers. The tool includes myths like exposure to electromagnetic frequencies, consuming additives meals or food containing artificial sweeteners or genetically modified food, living near powerline, stress emotion, trauma to any parts of the body, drink from plastic bottles, usage of the cleansing product, mobile smartphone, aerosol containers \& microwave oven. Past research stated that faith about malignancy might cause mindfulness in an individual who can encourage them to do an early screening. Hence, this clarified the differences between early diagnosed malignancy and latediagnosed malignancy cases. Nonetheless, the prevalence of faith can vary from place to place that affected by some sociodemographic variables, and it may change over a period of time 5. Subsequently, it is critical to survey people's faith in mythical causes of malignancy in order to assess cancer awareness among the population. 
This is due to the influence of their belief on the choice of treatment, hence enhancing appropriate strategies in dealing with the cancer cases ${ }^{6}$. The aim of the current study was to find out the level of awareness and belief about breast cancer among women in Selangor, Malaysia.

\section{METHODS}

A cross-sectional study was conducted among 483 women living in Selangor using self-administered questionnaires that consist of sociodemographic details as well as awareness and belief regarding breast cancer. The inclusion criteria include women living in Selangor and age ranging from 18 to 65 years old while exclusion criteria those who have a mental disability, a male and those who refused to give consent. Data was collected using non-probability convince sampling at a Private clinic in Selangor.

Sample size was calculated using single population proportion formula and based on prevalence from previous study $p=0.607^{3}$. Total sample size required is 440 respondents.

$$
\begin{array}{ll}
\text { - } & N=\frac{\left[\mathrm{z}^{2}(\mathrm{p}(1-\mathrm{p}))\right]}{\mathrm{d}^{2}} \\
\text { - } & N=\frac{\left[1.96^{2}(0.607(1-0.607))\right]}{0.05^{2}} \quad \mathrm{~N}=367+20 \% \text { non } \\
& \text { respondents }=440
\end{array}
$$

Questionnaires consist of Part A, B and C. Part A consist part A1 which is about socio-demographic characteristics such as age, race, marital status, family income, education level and occupation. While Part A2 is about family and past medical history. Part A3 is about the source of information. While part $B$ is about awareness of breast cancer among women in Selangor and it was adopted from (Hasan et al., 2017) ${ }^{7}$ the total number of questions is 18 . It consists of 3 parts which are sign and symptoms, risk factors and protective factors. The cut-off value is 9 . So those who answered more than $50 \%$, which is $>9$ is considered as having good awareness level. Part C is about the belief of breast cancer and it was adopted from Smith et al., 2018. The total number of questions is 12 , in which options scoring as follow: not sure, agree, strongly agree is incorrect $=0$, strongly disagree or disagree is correct $=1$ score. The cut off value is 6 so those who scored $>6$ is considered as having good belief ${ }^{5}$. All respondents will fill up a consent form before the questionnaire. Ethical approval was obtained by Management and Science University (MSU-RMC-02/FR01/04/L1/004). All details will be used for research only.

\section{Statistical analysis}

Data were analysed using JASP version 0.10 software ${ }^{8}$. Frequency, percentage, mean and SD were used in descriptive statistics while chi square analysis was used to examine associations between breast cancer awareness and sociodemographic characteristics of the respondents.

\section{RESULTS}

In our study, the mean age of the women was $32.81 \pm 12.90$. Most of the respondents were Malay $54.0 \%$ followed by Indian and Chinese $29.0 \%, 14.4 \%$ respectively. The majority of women were single, having university degree $(75.5 \%)$ as shown in table 1 . Regarding the breast cancer awareness, out of 483 participants, 350 (72.5\%) are aware that painless lump in the breast is a symptom of breast cancer whereas $341(70.6 \%)$ respondents stated it is true that bloody secretions from the nipples also a symptom of breast cancer. However, more than one-third of them, which is around 189 of them stated that they were not aware of oedema in the arm and pitting in the areola as a symptom of breast cancer. More than half of the respondents stated true for the presence of a lump in the armpit and change in breast size with a percentage of $57.6 \%$ and $53.2 \%$ respectively as shown in table $2 \mathrm{~A}$.

Three hundred sixty-six respondents stated that having a positive family history as one of the risks of breast cancer with the highest percentage of $75.8 \%$. Almost half of the participants $(43.5 \%)$ were not aware that using contraceptive pills has a higher risk of developing breast cancer. Many stated that late marriage is not a risk factor in developing breast cancer with a percentage of $40.0 \%$. Only $25.1 \%$ aware that irregular menstrual cycle as a risk factor with a frequency of 121 respondents as shown in table $2 \mathrm{~B}$.

Out of 483 respondents, 274 participants with a percentage of $72.9 \%$ highly aware that proper nutrition and being physically active could protect against breast cancer. Followed by the second highest, about $56.7 \%$ of the respondents are aware that breastfeeding can be one of the protective measures. Only a few were aware that early menopause and late menstruation could protect against this with respondents of 92 and 93 respectively. Most of the respondents had heard about breast self-examination with the frequency of 394 and $81.6 \%$. However, about 123 with a percentage of $52.8 \%$, they are not very often to practised breast self-examination. This is because they do not know the technique with the frequency of 171 and $68.4 \%$ respectively based on Table 3. While for awareness about the mammogram, about 338 with a percentage of $70.0 \%$ had heard about mammogram but did not do a mammogram before with frequency of 405 and $83.9 \%$ respectively. 
Table 1: Socio-demographic characteristics of the respondents

\begin{tabular}{llllll}
\hline Variable & N & $\%$ & Min & Max & Mean (SD) \\
\hline Age & & & 18.0 & 65.0 & 32.81 (12.90) \\
Race & 261 & 54.0 & & & \\
Malay & 69 & 14.3 & & & \\
Chinese & 29 & 29.0 & & \\
Indian & 13 & 2.7 & & \\
Others & & & & \\
Marital status & 198 & 41.0 & & \\
Married & 10 & 2.1 & & \\
Divorced & 264 & 54.6 & & \\
Single & 11 & 2.3 & & \\
Widow & & & & \\
Educational level & 9 & 1.9 & & \\
No formal education & 10 & 2.1 & & \\
Primary & 99 & 20.5 & & \\
Secondary & 365 & 75.5 & & \\
University & & & & \\
Occupation & 88 & 18.2 & & \\
Government servant & 61 & 12.6 & & \\
Housewife & 136 & 28.2 & & \\
Private employer & 198 & 41.0 & & \\
Student & & & \\
Family history of breast cancer & 118 & 24.4 & & \\
Yes & 365 & 75.6 & & \\
No & & & & \\
\hline
\end{tabular}

Table 2a: Awareness regarding breast cancer among females in Selangor

\begin{tabular}{lll}
\hline Sign and symptoms & $\mathrm{N}$ & $\%$ \\
& & \\
\hline Painless lump in the breast & & 17.8 \\
Don't know & 86 & 9.7 \\
False & 47 & 72.5 \\
True * & 350 & \\
Bloody secretions from the nipples & & 23.8 \\
Don't know & 115 & 5.6 \\
False & 27 & 70.6 \\
True * & 341 & \\
& & 39.1 \\
Oedema in the arm & 189 & 19.7 \\
Don't know & 95 & 41.2 \\
False & 199 & \\
True * & & 39.1 \\
Pitting in the areola & 189 & 13.7 \\
Don't know & 66 & 47.2 \\
False & 228 & \\
True * & & 27.7 \\
Lump in armpit & 134 & 14.7 \\
Don't know & 71 & 57.6 \\
False & 278 & \\
True * & & 26.3 \\
Change in breast size & 127 & 53.2 \\
Don't know & 99 & \\
False & 257 & \\
True * & & \\
\hline
\end{tabular}


Table 2b: Awareness regarding breast cancer among females in Selangor

\begin{tabular}{|c|c|c|}
\hline Risk factors & $N$ & $\%$ \\
\hline \multicolumn{3}{|c|}{ Use of contraceptive pills } \\
\hline Don't know & 210 & 43.5 \\
\hline False & 102 & 21.1 \\
\hline True * & 171 & 35.4 \\
\hline \multicolumn{3}{|c|}{ Positive family history } \\
\hline Don't know & 58 & 12.0 \\
\hline False & 59 & 12.2 \\
\hline True * & 366 & 75.8 \\
\hline \multicolumn{3}{|c|}{ Using infertility drugs } \\
\hline Don't know & 231 & 47.8 \\
\hline False & 117 & 24.2 \\
\hline True * & 135 & 28.0 \\
\hline \multicolumn{3}{|c|}{ Irregular menstrual cycle } \\
\hline Don't know & 195 & 30.4 \\
\hline False & 167 & 34.6 \\
\hline True * & 121 & 25.1 \\
\hline \multicolumn{3}{|c|}{ Late marriage } \\
\hline Don't know & 180 & 37.3 \\
\hline False & 193 & 40.0 \\
\hline True * & 110 & 22.8 \\
\hline \multicolumn{3}{|c|}{ First child at older age } \\
\hline Don't know & 176 & 36.4 \\
\hline False & 183 & 37.9 \\
\hline True * & 124 & 25.7 \\
\hline \multicolumn{3}{|c|}{ Protective factors } \\
\hline \multicolumn{3}{|c|}{ Breast feeding } \\
\hline Don't know & 130 & 26.9 \\
\hline False & 79 & 16.4 \\
\hline True * & 274 & 56.7 \\
\hline \multicolumn{3}{|c|}{ Good nutrition and physically active } \\
\hline Don't know & 72 & 14.9 \\
\hline False & 59 & 12.2 \\
\hline True * & 352 & 72.9 \\
\hline \multicolumn{3}{|c|}{ Late menstruation } \\
\hline Don't know & 222 & 46.0 \\
\hline False & 168 & 34.8 \\
\hline True * & 93 & 19.3 \\
\hline \multicolumn{3}{|c|}{ Early menopause } \\
\hline Don't know & 251 & 52.0 \\
\hline False & 140 & 29.0 \\
\hline True * & 92 & 19.0 \\
\hline \multicolumn{3}{|c|}{ Pregnancy earlier than 40 years } \\
\hline Don’t know & 254 & 52.6 \\
\hline False & 120 & 24.8 \\
\hline True * & 109 & 22.6 \\
\hline \multicolumn{3}{|c|}{ Early marriage } \\
\hline Don't know & 222 & 46.0 \\
\hline False & 157 & 32.5 \\
\hline True * & 104 & 21.5 \\
\hline
\end{tabular}


According to table $4 \mathrm{~A}$, about $48.4 \%$ with a frequency of 234 respondents highly belief that is eating food containing additives, followed by eating food containing artificial sweeteners with $39.3 \%$ might cause breast cancer. Participants also believed that being stressed could also be one of the factors with $38.1 \%$.

Many believe that physical trauma (29.4\%) followed by using microwave ovens (21.1\%), then using mobile phones $(20.1 \%)$ could not be a factor. The highest number of participants with a frequency of 284 respondents $(58.8 \%$ ) were not sure of using aerosol containers can be one of the causes of breast cancer as shown in table 4B. This was followed by usage of microwave ovens with $46.6 \%$ then, living near power lines with $46.0 \%$. Almost half of the respondents with a frequency of $217(44.9 \%)$ were not sure about using clean products could cause this cancer. About 81 of the participants, with $16.8 \%$ strongly agreed that eating food containing additives influences the risk of developing breast cancer. About $7.9 \%$ were firmly disagreed the fact that living near power lines could be the reason for this problem as shown in table $4 \mathrm{~A}$.

Table 3: Awareness about breast self-examination and mammogram among females in Selangor

\begin{tabular}{|c|c|c|}
\hline & $\mathbf{N}$ & $\%$ \\
\hline \multicolumn{3}{|c|}{ Heard of breast self-examination } \\
\hline Yes & $\begin{array}{l}89 \\
394\end{array}$ & $\begin{array}{l}18.4 \\
81.6\end{array}$ \\
\hline \multicolumn{3}{|l|}{ Heard of mammogram } \\
\hline No & 145 & 30.0 \\
\hline Yes & 338 & 70.0 \\
\hline \multicolumn{3}{|c|}{ Perform breast self-examination } \\
\hline Yes & $\begin{array}{l}250 \\
233\end{array}$ & $\begin{array}{l}51.8 \\
48.2\end{array}$ \\
\hline \multicolumn{3}{|c|}{ How often breast self-examination is practised } \\
\hline \multicolumn{3}{|c|}{ More than once in quarter of a year } \\
\hline Not very often & 25 & 10.7 \\
\hline Once in 3 months & 123 & 52.8 \\
\hline Once in a month & $\begin{array}{l}77 \\
8\end{array}$ & $\begin{array}{l}33 \\
3.4\end{array}$ \\
\hline \multicolumn{3}{|l|}{ Reason for not doing } \\
\hline Afraid of finding a lump & 22 & 8.8 \\
\hline I don't the technique & 171 & 68.4 \\
\hline I don't trust my examination & 26 & 10.4 \\
\hline I don't think it is of benefit & 31 & 12.4 \\
\hline \multicolumn{3}{|l|}{ Did Mammogram before } \\
\hline No & 405 & 83.9 \\
\hline Yes & 78 & 16.1 \\
\hline \multicolumn{3}{|c|}{ Breast examination by specialist } \\
\hline No & 387 & 80.1 \\
\hline Yes & 96 & 19.9 \\
\hline
\end{tabular}

From table 5 , it is shown that education level $(P=0.001)$ and family history of breast cancer $(\mathrm{P}=0.032)$ have a significant association with awareness compared to race $(\mathrm{P}=0.392)$ and marital status $(\mathrm{P}=0.333)$ Among the races, Indians has good awareness with, $\mathrm{N}=39.3 \%$ followed by other race with $\mathrm{N}=38.5 \%$. However, Chinese women have an inferior awareness, with $\mathrm{N}=72.5 \%$ about breast cancer. Single women have very good awareness, with $38.3 \%$ and least awareness among divorced women. Women who went to university have a good awareness (41.4\%) when compared to those who have no formal education with poor awareness of $88.9 \%$. Those with positive family history has a good awareness (44.9\%) compared to those who do not have any family history. Respondents those who gain a source of information about breast cancer via primary healthcare centres have good awareness with $56.0 \%$, followed by their education with $52.3 \%$. However, those who gain a source of information via television and friends have a very poor awareness with $63.2 \%$ and $63.0 \%$ respectively. 
Table 4a: Beliefs regarding breast cancer among females in Selangor

Frequency Percentage

\section{Exposure to electromagnetic force}

\section{Agree}

Disagree

Not sure

154

31.9

Strongly Agree

78

16.1

Strongly Disagree

163

33.7

64

13.3

24

5.0

\section{Eating food containing additives}

\section{Agree}

234

51

48.4

Disagree

96

10.6

Not sure

81

19.9

Strongly agree

Strong disagree

16.8

4.3

\section{Living near power lines}

\section{Agree}

Disagree

Not sure

Strongly agree

Strongly disagree

Feeling stressed

Agree

Disagree

Not sure

Strongly agree

Strongly disagree

Eating food containing artificial sweeteners

\section{Agree}

Disagree

Not sure

Strongly agree

Strongly disagree

\section{Using cleaning product}

Agree

Disagree

Not sure

Strongly agree

Strongly disagree
100

91

222

38

32

184

66

144

69

20

190

53

155

69

16

95

116

217

30

25
20.7

18.8

46.0

7.9

6.6
38.1

13.7

29.8

14.3

4.1
39.3

11.0

32.1

14.3

3.3

19.7

24.0

44.9

6.2

5.2 
Table 4b: Beliefs regarding breast cancer among females in Selangor

Using mobile phones

Agree

Disagree

Not sure

Strongly agree

42

8.7

Strongly disagree

Eating genetically modified food

Agree

Disagree

Not sure

Strongly agree

Strongly disagree

\section{Using aerosol containers}

$\begin{array}{lll}\text { Agree } & 91 & 18.8 \\ \text { Disagree } & 77 & 15.9 \\ \text { Not sure } & 284 & 58.8 \\ \text { Strongly agree } & 16 & 3.3 \\ \text { Strongly disagree } & 15 & 3.1\end{array}$

\section{Physical trauma}

\section{Agree}

Disagree $\quad 84$

17.4

Not sure

Strongly agree

Strongly disagree

\section{Using microwave ovens}

$\begin{array}{ll}\text { Agree } & 103 \\ \text { Disagree } & 102 \\ \text { Not sure } & 225 \\ \text { Strongly agree } & 26 \\ \text { Strongly disagree } & 27\end{array}$

Drinking from plastic bottles

$\begin{array}{ll}\text { Agree } & 158 \\ \text { Disagree } & 79 \\ \text { Not sure } & 188 \\ \text { Strongly agree } & 37 \\ \text { Strongly disagree } & 2\end{array}$

$\begin{array}{ll}188 & 38.9\end{array}$

$\begin{array}{ll}37 & 7.7\end{array}$

$21 \quad 4.3$

The association between awareness and belief regarding breast cancer was highly significant $(P=$ 0.02 ). Most of the respondent has poor awareness and poor belief with 268 and $65 \%$ respectively shown in Table 6.

\section{DISCUSSION}

The main finding of our research was that the awareness of breast cancer was inadequate or unsatisfying as most of the respondents did not know the various signs, symptoms, risk factors and protective factors of breast cancer. However, the level of breast self -examination practice was low, signifies that the practice of breast self - 
examination is not extensive. Few studies have shown that Asian women have low to moderate knowledge with weak to moderate breast self examination practice ${ }^{9-13}$. In our research, most of the respondents had heard of breast selfexamination (81.6\%) and mammogram (70\%). However, among a total of 484 respondents, only 171 respondents $(36.6 \%)$ have a good awareness of breast cancer, while 306 respondents (63.4\%) have poor awareness of breast cancer.

In our study, knowledge about signs, symptoms, risk factors and protective factors of breast cancer was investigated. The majority of respondents knew about a few signs and symptoms of breast cancer such painless lump in the breast $(72.5 \%)$, bloody secretions from the nipples (70.6\%). However, other signs and symptoms like oedema in the arm (41.2\%), pitting in the areola (47.2\%), a lump in armpit (57.6\%) and changing breast size (53.2\%) were not recognized by the majority of respondents. A previous study in Malaysia also showed a similar finding of high knowledge about blood discharge as a symptom of breast cancer and low knowledge about nipple retraction ${ }^{14}$. A recent study in Singapore found that the most frequent symptoms recognized by respondents were palpable breast lump and nipple discharge. A similar finding was reported whereby a significant increase in the awareness and practices of BSE by $43 \%$ and $53 \%$ respectively were observed after the interventional health education was administered among women in a semi-urban area of India ${ }^{15}$. According to our research, the most common reason for not performing breast self-examination is not knowing the technique $(68.4 \%)$ followed by not thinking it is of benefit (12.4\%), not trusting the examination (10.4\%) and afraid of finding lump (8.8\%).

Table 5: The association between socio-demographic factors and awareness about breast cancer among females in selangor

\begin{tabular}{|c|c|c|c|c|c|c|}
\hline \multirow[t]{3}{*}{ Social demographic } & \multicolumn{4}{|c|}{ Awareness } & \multirow[t]{3}{*}{$\mathrm{X} 2$} & \multirow[t]{3}{*}{$\mathbf{P}$} \\
\hline & \multicolumn{2}{|l|}{ Poor } & \multicolumn{2}{|c|}{ Good } & & \\
\hline & $\mathbf{N}$ & $\%$ & $\mathbf{N}$ & $\%$ & & \\
\hline \multicolumn{7}{|l|}{ Race } \\
\hline Malay & 163 & 62.5 & 98 & 37.5 & 2.996 & 0.392 \\
\hline Chinese & 50 & 72.5 & 19 & 27.5 & & \\
\hline Indian & 85 & 60.7 & 55 & 39.3 & & \\
\hline Others & 8 & 61.5 & 5 & 38.5 & & \\
\hline \multicolumn{7}{|l|}{ Marital status } \\
\hline Divorced & 9 & 90.0 & 1 & 10 & 3.407 & 0.333 \\
\hline Married & 127 & 64.1 & 71 & 35.9 & & \\
\hline Single & 163 & 61.7 & 101 & 38.3 & & \\
\hline Widowed & 7 & 63.6 & 4 & 36.4 & & \\
\hline \multicolumn{7}{|l|}{ Education level } \\
\hline No formal education & 8 & 88.9 & 1 & 11.1 & 16.24 & $0.001^{*}$ \\
\hline Primary school & 6 & 60.0 & 4 & 40.0 & & \\
\hline Secondary school & 78 & 78.8 & 21 & 21.2 & & \\
\hline University & 214 & 58.6 & 151 & 41.4 & & \\
\hline \multicolumn{7}{|l|}{$\begin{array}{l}\text { Family history of } \\
\text { breast cancer }\end{array}$} \\
\hline No & 241 & 66.0 & 124 & 34.0 & 4.559 & $0.032^{*}$ \\
\hline Yes & 65 & 55.1 & 53 & 44.9 & & \\
\hline
\end{tabular}

${ }^{*}$ Chi square test was performed. Level of significance at $p<0.05$

As for the risk factors of developing breast cancer, the vast majority of respondents answered a positive family history of breast cancer (75.8\%). However, many did not recognize other risk factors such as the use of contraceptive pills, using infertility drugs, irregular menstrual cycle, late marriage and having a first child at older age. $72 \%$ of respondents answered proper nutrition and being physically active reduces the risk of breast cancer.56.7\% of respondents recognized breastfeeding as a protective factor for developing breast cancer. However protective factors such as late menstruation (19.3\%), early menopause (19\%), pregnancy earlier than 40 years of age $(22.6 \%)$ and early marriage $(21.5 \%)$ were recognized by a minority of respondents. Inadequate knowledge about risk factors of breast cancer was also reported by previous researches, not only among the general population 16,17, female teachers and health providers such as nurses were found to have inadequate knowledge on breast cancer ${ }^{14,18}$. These two previous studies 
have found that only $55.0 \%$ of Malaysian teachers 14 and $35.0 \%$ of Pakistani nurses had good knowledge on risk factors of breast cancer ${ }^{18}$. Those studies also have found that breastfeeding, age of menopause and menarche were not recognized as risk factors of breast cancer by the majority of respondents.

Table 6: Association between awareness and belief regarding breast cancer among females in selangor

\begin{tabular}{|c|c|c|c|c|c|c|}
\hline \multirow{3}{*}{ Belief Level } & \multicolumn{4}{|c|}{ Awareness Level } & $\mathrm{X} 2$ & P Value \\
\hline & Poor & & Gooc & & & \\
\hline & $\mathbf{N}$ & $\%$ & $\mathbf{N}$ & $\%$ & & \\
\hline Poor & 268 & 65.0 & 141 & 35.0 & 5.423 & $0.020^{*}$ \\
\hline Good & 38 & 51.4 & 36 & 48.6 & & \\
\hline
\end{tabular}

${ }^{*}$ Chi square test was performed. Level of significance at $p<0.05$.

Based on a study done in 2018, it was found that participants have myths like exposure to electromagnetic frequencies, consuming additives meals or food containing artificial sweeteners or genetically modified food, living near powerline, stress emotion, trauma to any parts of the body, drink from plastic bottles, usage of cleansing product, mobile smartphone, aerosol containers \& microwave oven ${ }^{5}$. According to our research done on beliefs regarding breast cancer, about $48.4 \%$ with a frequency of 234 respondents highly belief that eating food containing additives, then about $39.5 \%$ belief eating genetically modified food and followed by eating food containing sweeteners with $39.3 \%$ might cause breast cancer. Feeling stressed also believed could be one of the factors with a percentage of $38.1 \%$. However, many participants believe that exposure to electromagnetic with $33.7 \%$, using a mobile phone with $(20.1 \%)$ and physical trauma with $(40.8 \%)$ could not be a factor causing breast cancer. The highest number of respondents, with $58.8 \%$ were not sure about using aerosol containers. This was followed by living near power lines (46.0\%) and using cleaning products (44.9\%). Most of the respondents (65\%) are found to have poor awareness with poor belief, followed by $51.4 \%$ who have poor awareness with good belief, good awareness with good belief (48.6\%) and 34.5\% having good awareness with poor belief. Lastly, the association between awareness and belief regarding breast cancer was highly significant

\section{CONCLUSION}

In conclusion, the level of poor awareness is $63.4 \%$, while the level of poor belief is $84.7 \%$. This study shows that the internet plays a significant role as a source of information of breast cancer among females in Selangor. Thus, more education should be done using the media to increase the level of awareness and belief on breast cancer.

\section{Conflict of interest}

The authors declare no potential conflict of interest.

\section{REFERENCES}

1. World Health Organization. Breast cancer facts. Retrived from https: / / www. who.int/cancer/preven tion/diagnosis-screening/breastcancer/en/

2. Majlis Kanser Nasional, MAKNA Annual report , 2017

3. Hadi, M. A., Hassali, M. A., Shafie, A. A. , \& Awaisu, A. (2010). Evaluation of breast cancer awareness among female university students in Malaysia. Pharmacy Practice, 8(1), 29-34.

https: / / doi.org/10.4321/S1886-

36552010000100003

4. Al-Dubai SAR, Qureshi AM, Ali RS, et al (2011). Awareness and knowledge of breast cancer and mammography among a group of Malaysian women in Shah Alam. APJCP, 12, 2531-8

5. Smith, S. G., Beard, E., Mcgowan, J. A., Fox, E., Cook, C., Pal, R., ... Shahab, L. (2018). Development of a tool to assess beliefs about mythical causes of cancer: the Cancer Awareness Measure Mythical Causes Scale. 1-10. https://doi.org/10.1136/bmjopen2018-022825

6. Panjari, M., Davis, S. R., Fradkin, P., \& Bell, R. J. (2012). Breast cancer survivors' beliefs about the causes of breast cancer. Psycho-Oncology, 21(7), 724-729. https: / /doi.org/10.1002/pon.1949

7. Hasan TN, Shah SA, Hassan MR, Safian N, Azhar ZI, Syed Abdul Rahim SS, Ghazi HF. Poor Knowledge and Practice Towards Breast Cancer among Women in Baghdad City, Iraq. Asian Pac J Cancer Prev. 2015; 16(15):6669-72. 
8. JASP Statistical software . https: / / jasp-stats.org

9. Jarvandi S, Montazeri A, Harirchi I, et al (2002). Beliefs and behaviours of Iranian teachers toward early detection of breast cancer and breast self-examination. Public Health, 116, 245-9

10. Parisa Parsa and Mirnalini Kandiah. Breast cancer knowledge, perception and breast self-examination practices among Iranian women. The international medical journal 2005 , $4(2): 17-24$

11. Tavafian SS, Hasani L, Aghamolaei T, Zare S, Gregory D. Prediction of breast self-examination in a sample of Iranian women: an application of the Health Belief Model. BMC Women's Health. 2009;9(1):37.

12. Hassan MR, Ghazi HF, Mohamed AS, Jasmin SJ (2017) Knowledge and practice of breast self-examination among female non-medical students in universiti Kebangasaan Malaysia (UKM) in Bangi. Malaysian Journal of Public Health Medicine 17: 51-58.

13. Hasanain Faisal Ghazi, Maged Elnajeh, Afifah Azri, Mohammed A. AbdalQader, Mohammed Faez Baobaid, Al-abed Ali Ahmed Al-abed. knowledge and beliefs on female breast cancer among male students in a private University, Malaysia
Malaysian Journal of Public Health Medicine 2017; 17(1):8-13.

14. Parsa P, Kandiah M, Mohd Zulkefli NA, et al (2008). Knowledge and behavior regarding breast cancer screening among female teachers in Selangor, Malaysia. Asian Pac J Cancer Prev, 9, 221-7.

15. Gupta SK, Pal DK, Grag R, et al (2009). Impact of a health education intervention program regarding breast self-examination by women in a semi-urban area of Madhya Pradesh, India. Asia Pac J Cancer Prev, 10, 1137.

16. Alam AA. Knowledge of breast cancer and its risk and protective factors among women in Riyadh. Ann Saudi Med. 2006;26(4):272.

17. Amin TT, Al Mulhim A, Al MA. Breast cancer knowledge, risk factors and screening among adult Saudi women in a primary health care setting. Asian Pac J Cancer Prev. 2009;10(1):133-8.

18. Ahmed F, Mahmud S, Hatcher J, Khan SM (2006). Breast cancer risk factor knowledge among nurses in teaching hospitals of Karachi, Pakistan: a cross-sectional study. BMC Nurs, 5, 6 